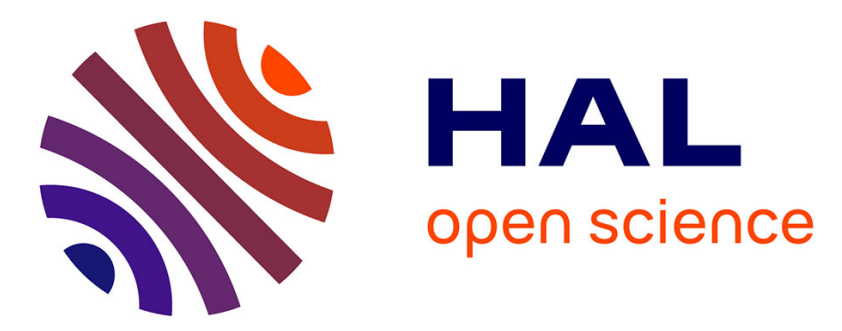

\title{
Amazonian species within the Cerrado savanna: new records and potential distribution for Aglae caerulea (Apidae: Euglossini)
}

Daniel Silva, Antonio Aguiar, Gabriel Melo, Evandson Anjos-Silva, Paulo

Marco

\section{To cite this version:}

Daniel Silva, Antonio Aguiar, Gabriel Melo, Evandson Anjos-Silva, Paulo Marco. Amazonian species within the Cerrado savanna: new records and potential distribution for Aglae caerulea (Apidae: Euglossini). Apidologie, 2013, 44 (6), pp.673-683. 10.1007/s13592-013-0216-7 . hal-01201337

\section{HAL Id: hal-01201337 \\ https://hal.science/hal-01201337}

Submitted on 17 Sep 2015

HAL is a multi-disciplinary open access archive for the deposit and dissemination of scientific research documents, whether they are published or not. The documents may come from teaching and research institutions in France or abroad, or from public or private research centers.
L'archive ouverte pluridisciplinaire HAL, est destinée au dépôt et à la diffusion de documents scientifiques de niveau recherche, publiés ou non, émanant des établissements d'enseignement et de recherche français ou étrangers, des laboratoires publics ou privés. 


\title{
Amazonian species within the Cerrado savanna: new records and potential distribution for Aglae caerulea (Apidae: Euglossini)
}

\author{
Daniel P. Silva ${ }^{1}$, Antonio J. C. Aguiar ${ }^{2}$, Gabriel A. R. Melo ${ }^{3}$, \\ Evandson J. Anjos-Silva ${ }^{4}$, Paulo De Marco Jr${ }^{5}$ \\ ${ }^{1}$ Programa de Pós-Graduação em Ecologia e Evolução, Departamento de Ecologia, ICB, Universidade Federal de \\ Goiás, Rodovia Goiânia-Nerópolis, Km 5, Campus II, Setor Itatiaia, CEP: 74001-970 Goiânia, GO, Brazil \\ ${ }^{2}$ Departamento de Zoologia, Universidade de Brasília, IB-UnB, Campus Darcy Ribeiro, Asa Norte, CEP: 70910- \\ 900 Brasília, DF, Brazil \\ ${ }^{3}$ Lab. Biol. Comparada Hymenoptera, Setor de Ciências Biológicas, Departamento de Zoologia, Universidade \\ Federal do Paraná, Caixa Postal 19020, CEP 81531-990 Curitiba, PR, Brazil \\ ${ }^{4}$ Lab. de Abelhas e Vespas Neotropicais, Departamento de Biologia, Universidade do Estado de Mato Grosso, \\ Avenida Tancredo Neves s/n, Cavalhada, CEP: 78200-000 Cáceres, MT, Brazil \\ ${ }^{5}$ Departamento de Ecologia, ICB, Universidade Federal de Goiás, Rodovia Goiânia-Nerópolis, Km 5, Campus II, \\ Setor Itatiaia, CEP: 74001-970 Goiânia, GO, Brazil
}

Received 21 December 2012 - Revised 7 May 2013 - Accepted 22 May 2013

\begin{abstract}
Given human-related changes, quality distributional data are required for consistent conservation. Still, the lack of proper biogeographic information is a major setback for many groups. Here, we use new occurrences for Aglae caerulea in the Cerrado to model its potential distribution. We used Maximum Entropy (MaxEnt) and Genetic Algorithm for Rule-Set Production (GARP) algorithms in different modeling runs and both previous and new $A$. caerulea occurrences to predict this species distribution. Models which used only the previous A. caerulea's records did not predicted the new Cerrado records, while those where we used the latter did predict the new ones as minimally suitable. A. caerulea distribution significantly increased towards the Cerrado according to both MaxEnt and GARP algorithms. Gallery forests are important dispersal alternatives for several species dwelling the Amazon and the Atlantic forest. Niche models of other rare Euglossini bees are advised to better evaluate their distributions.
\end{abstract}

Aglae caerulea / Amazon / Cerrado / dispersal corridor / Wallacean shortfall / species distribution modeling

\section{INTRODUCTION}

In a continuously changing world, which is directly and indirectly affected by human activities (Tylianakis et al. 2008; Dobrovolski et al. 2011), high-quality distributional data are essential to help on the task of setting priorities and efficient conservation actions (Myers et al. 2000;

Corresponding author: D.P. Silva, daniel.paivasilva@gmail.com

Manuscript Editor: Klaus Hartfelder
Whittaker et al. 2005; Brooks et al. 2006). Still, the Wallacean shortfall, i.e., lack of proper biogeographic information, is one of the major setbacks hampering conservation actions (Bini et al. 2006). Such situation is even worse in megadiverse but poorly sampled tropical regions (Newbold 2010; Kamino et al. 2011), which usually lack extensive biogeographic information but suffer deep and fast environmental changes (Bawa et al. 2004; Hong and Lee 2006).

Beside their diversity, insects and other terrestrial invertebrates play several important 
ecosystemic roles (e.g., pollination, plague control, nutrient cycling). However, they have been usually neglected in conservation actions (Diniz-Filho et al. 2010a; Cardoso et al. 2011). Even insect groups with extensive taxonomic, biological, and ecological data available (e.g., ants, bees, odonates, and butterflies) lack consistent biogeographic data (Diniz-Filho et al. 2010a; Vianna and De Marco Jr 2012). Despite such problems, Diniz-Filho et al. (2010a) provided an optimistic view on how to use theoretical approaches and modern methods to conserve insects, such as ecological niche models (ENM). Based on statistically or derived response surfaces, ENMs relate presence records of a given species to the available predictor variables from those places where it was sampled to predict environmentally suitable areas for its occurrence (Guisan and Zimmermann 2000). Consequently, it is possible to fill gaps in the biogeographic knowledge concerning species distribution and improve the implementation of conservation actions (Nóbrega and De Marco Jr 2011).

Considering that species distribution is delimited by the intersection of environmentally suitable, biologically available, and biogeographically/historically reachable habitats (Soberón 2007), ENMs are useful tools in the attempt to overcome Wallacean shortfall and implement insect-oriented biogeography conservation plans (Diniz-Filho et al. 2010a). ENM techniques have been used quite often to study insects, particularly due to the following reasons: (1) determine potential distribution of taxa given new occurrences (Almeida et al. 2010), (2) assess suitable areas for future samplings (Diniz-Filho et al. 2010b), (3) pinpoint areas for the implementation of new conservation units (Nóbrega and De Marco Jr 2011), and (4) determine areas prone to invasion of alien species (Mata et al. 2010) or suitable for species distribution under different global warming scenarios (Giannini et al. 2012).

Considering new distributional data for the orchid bee Aglae caerulea Lepeletier and Serville (Apidae: Euglossini) outside its previously known core Amazonian distribution (see below), here we use both previous and new distribution data to deal with two questions.
Initially, we assess whether previous occurrences of $A$. caerulea are sufficient to predict the new information obtained for the Cerrado biome and a doubtful Panamanian record (Moure 1967; Cameron 2004; Michener 2007). If they do, dispersal of $A$. caerulea from its core distribution can be considered the only process accounting for the new data. If they do not, we evaluate whether the inclusion of the new occurrences increases the total distribution for this species, pinpointing new suitable areas outside the Amazon for A. caerulea. Second, considering all $A$. caerulea occurrences, we evaluate its possible dispersal paths from its core distribution in the Amazon basin through the Cerrado, with particular attention to the role of riparian areas of large rivers.

\section{MATERIAL AND METHODS}

\subsection{A. caerulea and its known distribution}

Different from the other Euglossini bees, the rarely sampled $A$. caerulea has a long (23-25 mm long), slender, and flattened body and slender hind legs (Cameron 2004). The only bionomical observations available for this species indicate that it parasitizes nests of Eulaema bees (Myers 1935). Given its rareness in entomological collections and in Euglossini surveys using scent baits, it is considered to be a rare species in nature (Cameron 2004). Its distribution has been considered to be mostly restricted to the Amazon basin (Cameron 2004; Michener 2007). Nevertheless, this species has been lately sampled outside its Amazon core distribution in four different occasions (Anjos-Silva et al. 2006, and three new occurrences for the state of Goiás, Brazil, sampled by Silva, DP). Additionally, Moure (1967) reported its presence in Panama. Nonetheless, such occurrence has been flagged as uncertain since no other specimen of $A$. caerulea was sampled in that country again, even after decades of new surveys after the date of the first record (Cameron 2004).

We also compiled $A$. caerulea records from museum collections [(1) DZUP—Coleção Entomológica Padre J.S. Moure, Universidade Federal do Paraná, Curitiba, PR, Brazil; (2) RPSP—Coleção Camargo, Universidade de São Paulo, Ribeirão Preto, SP, Brazil; 
(3) MZUSP—Muzeu de Zoologia, Universidade de São Paulo, São Paulo, SP, Brazil; (4) COENTOL - Coleção Entomológica do Departamento de Biologia, Universidade do Estado de Mato Grosso, Cáceres, MT, Brazil], online data bases [(1) Discover Life Bee Species Guide and World Checklist (http:// www.discover-life.org); (2) Species Link (http:// splink.cria.org.br)], and literature (Morato 2001; Otero and Sandino 2003; Anjos-Silva et al. 2006). A total of 41 occurrences for $A$. caerulea were compiled, most of them in the Amazon basin, but with two records from the Choco region, in western Ecuador and southwestern Colombia. For records lacking the exact sampling site information, we used Google Earth (Google Inc. 2012) to find city center coordinates as a proxy information for sampling sites. The geographical coordinates of the three new A. caerulea occurrences found in Brazil may be found in the Supplementary Materials section (Table S1).

\subsection{Environmental data}

We derived seven environmental variables to be used in our ENM procedures and produce $A$. caerulea distribution models. Six of them [annual temperature, temperature seasonality (coefficient of variation), mean temperature of the driest quarter, annual precipitation, precipitation seasonality (coefficient of variation), and precipitation of the warmest quarter] were obtained from WorldClim (Hijmans et al. 2005; http: \www.worldclim.org). The last variable (terrain slope) was derived from Hydro-1K global digital elevation model (http://eros.usgs.gov). We selected these variables since they were already used as climate predictors in other studies which modeled insect distributions (e.g., Almeida et al. 2010; Serra et al. 2012). Once some of our occurrences were related to city center coordinates instead of actual GPS coordinates, we re-scaled all variables to a 5-min resolution $\left(0.0833^{\circ} \approx 8 \mathrm{~km}\right)$.

In order to define the location of the new A. caerulea occurrences in the species environmental space, we performed a principal components analysis (PCA) with all variables. Once all environmental variables had different units, prior to the analysis, we standardized them. We considered the Kaiser-Guttmann criterion (eigenvectors with eigenvalues higher than 1; PeresNeto et al. 2005) to retain the most important PCA eigenvectors. The cutoff loading to consider an environmental variable as influent in the PCA analysis was 0.6.

\subsection{Modeling procedures and model evaluation}

We divided the occurrence dataset into three categories: (1) "Previous" $(n=36)$, (2) "Cerrado" $(n=4)$, and (3) "Doubtful" Panamanian record $(n=1)$. In a first modeling run, we randomly split the previous and mostly Amazonian occurrences into $70 \%: 30 \%$ training/testing subsets and evaluated whether the training subset was able to predict the newer and the doubtful $A$. caerulea occurrences. In a second modeling run, we included all the new Cerrado occurrences in the training subset and reevaluated $A$. caerulea distribution considering a testing subset composed by $30 \%$ of all $A$. caerulea occurrences (except the newer and the Panamanian ones). Finally, we used all occurrences to predict the species distribution. The doubtful occurrence was never used in any of the modeling procedures. The modeling procedures are summarized in Figure S1.

We trained $A$. caerulea distribution models with two widely used algorithms: Maximum Entropy implemented in MaxEnt (Phillips et al. 2006; Phillips and Dudik 2008) and the Genetic Algorithm for RuleSet Production (GARP; Stockwell and Peters 1999) implemented in openModeller Desktop v.1.1.0 (Munoz et al. 2011). MaxEnt is a machine-learning presence/ pseudo-absence method which is very reliable when occurrence dataset have few and/or biased records (Pearson et al. 2007). We only modeled $A$. caerulea distributions with linear and quadratic features selected, to produce simpler biological models (Elith et al. 2011). GARP is a non-deterministic algorithm based in a random set of mathematical rules which may be interpreted as the limiting environmental conditions determining species occurrences (Stockwell and Peters 1999). Defining the area within which the species may potentially reach is an important step, while modeling species distribution, once the potential area the species may reach, is an important feature which affects the development of its ecological niche (Barve et al. 2011). Here, we trained the $A$. caerulea's distribution models using the whole extent of South America as the species maximum potential ranges. Although different biogeographic regions may be contemplated within this region (e.g., Amazon basin, Cerrado, Mata Atlântica; Nemésio 
and Silveira 2007), once the species was already sampled in two of those, to train the models considering the whole South American continent was advised and methodologically indicated.

Following Liu et al. (2011), we used both area under the receiver-operator curve (AUC) and true skilled statistics (TSS) to assess models performance. The AUC is a threshold-independent statistics varying from 0 to 1 . Values around 0.5 represent distribution models no better than random and values around 1 represent a perfect fitting between the observed and the predicted species distribution. Acceptable distribution models are those with values higher than 0.7 . TSS is a thresholddependent statistics which varies from -1 to +1 (Allouche et al. 2006). TSS values near 0 or negative represent distributions no better than random, while values equal to +1 represent a perfect agreement between the observed and the predicted distribution. We used 10,000 random pseudo-absences during model evaluation procedures.

We used the lowest predicted suitability value associated with a given observed presence record (lowest presence threshold-LPT; Pearson et al. 2007), to determine $A$. caerulea distribution generated by each modeling algorithm. Ecologically speaking, the LPT identifies the pixels predicted to be as minimally suitable for the species occurrence as its actual observed records. For the final $A$. caerulea distribution, we used a single mean consensus map between both modeling algorithms in order to determine $A$. caerulea distribution, considering the LPT values that each independent model (Maximum Entropy and GARP) obtained when all occurrences (including the new Cerrado records) were used. This consensus method considers the separated values in each grid cell for all predictions obtained from different modeling algorithms to determine the mean modeled species distribution. This method was considered to be one of the most robust while determining the agreement of species distributions (Marmion et al. 2009). For the sake of discussing the distribution of $A$. caerulea, considering its known occurrences and the known Euglossini sampling effort in South American, we also show the ensemble distribution obtained from the threshold derived from the "receiver-operator curve" (ROC; Liu et al. 2011). While LPT minimizes omission but maximizes commission errors, ROC balances both errors and produces smaller distributions when compared LPT.

\section{RESULTS}

We retained three eigenvectors from our PCA analysis (Figure 1; Table S2). Nevertheless, we only show the results comparing the first two eigenvectors because such interpretation is simpler and the other comparisons ( $\mathrm{PC1}$ vs. PC3 and PC2 vs. PC3) had similar results (Figure S2A-B). All new occurrences from Cerrado were separated from all previously known occurrences for $A$. caerulea. On the other hand, the doubtful Panamanian occurrence was always among the previous records for the modeled species (Figures 1 and S2A-B).

The four new $A$. caerulea occurrences considerably increased its distribution range, especially considering their distances to the nearest occurrence records previously sampled in the Amazon $[\sim 2,000 \mathrm{~km}$ for the occurrences in Goiás and $\sim 1,000 \mathrm{~km}$ for the one sampled by Anjos-Silva et al. (2006)]. Generally, the distribution models produced only with the previous occurrences showed a fair to good performance when considering both TSS and AUC values, respectively (Table I).

The doubtful Panamanian record was predicted as suitable for A. caerulea in all models (Figure 2). On the other hand, the models using only the previous occurrences as the training subset had a low predictive power regarding the new occurrences for the Cerrado savanna (Figure $2 \mathrm{a}-\mathrm{b}$ ). The model generated only with the previously known $A$. caerulea occurrences predicted areas in northern Peru, southeastern Colombia, northeastern Ecuador, southern Venezuela, and Amazonas and Para states in Brazil as suitable for A. caerulea.

The inclusion of the new Cerrado records had a great effect on models performance (Table I), with overall decreases in both AUC and TSS values. Although the new occurrences were predicted as minimally suitable in both modeling algorithms, they increased $A$. caerulea potential distribution by almost 30 and $50 \%$, according to GARP and MaxEnt, respectively (Figure 2c-d). After their inclusion, we observed additional range increases towards the Cerrado savanna and Bolivia. The Panamanian 


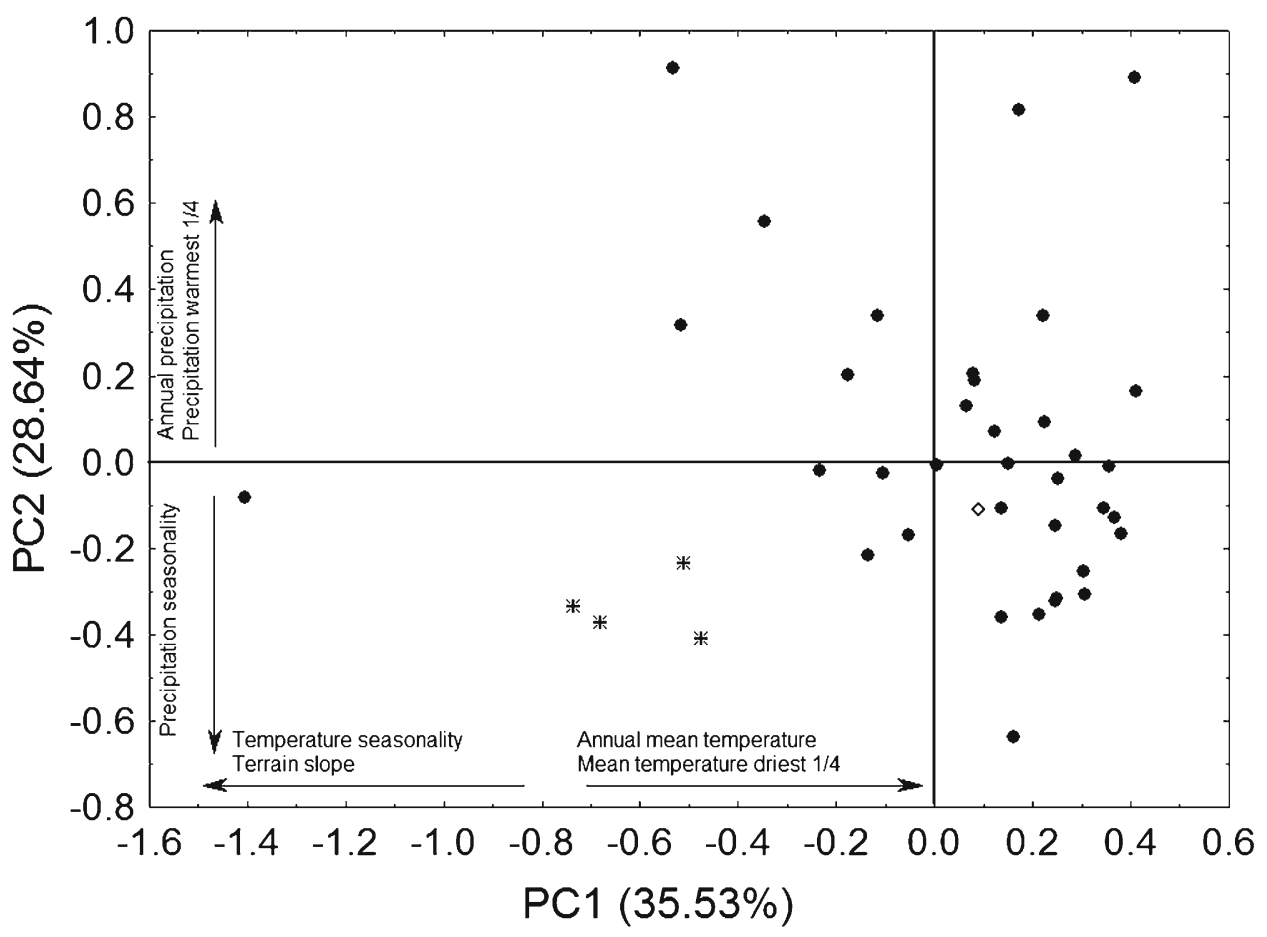

Figure 1. Principal components analysis results showing the separation of the new Cerrado occurrences (asterisks) from the previous ones (black circles) recorded for A. caerulea. Note that the doubtful Panamanian occurrence (diamonds) is suitable for A. caerulea occurrence. The arrows represent which environmental variables were positively and negatively related to each retained eigenvector. The percentages represent the amount of variation explained by each eigenvector.

occurrence was still predicted as suitable in both modeling algorithms and in the A. caerulea consensus map (Figure 3a, b).

Considering the consensus maps, although the LPT threshold minimally predicted the new occurrences records for $A$. caerulea within the Cerrado biome (Figure 3a), it also increased its distribution into arid areas in northwestern Venezuela and northern Colombia, where the species is assumed to be absent. On the other

Table I. Performance of $A$. caerulea models considering training subsets without and with the new occurrences from the Cerrado. The doubtful Panamanian occurrence was not used in the models.

\begin{tabular}{|c|c|c|c|c|c|c|}
\hline \multirow[b]{3}{*}{ Modeling algorithm } & \multirow{2}{*}{\multicolumn{2}{|c|}{$\begin{array}{l}\text { Amazonian occurrences } \\
(70: 30)\end{array}$}} & \multirow{2}{*}{\multicolumn{2}{|c|}{$\begin{array}{l}\text { All occurrences } \\
(70: 30)\end{array}$}} & \multirow{2}{*}{\multicolumn{2}{|c|}{$\frac{\text { All occurrences }}{(100: 100)}$}} \\
\hline & & & & & & \\
\hline & AUC & TSS & AUC & TSS & AUC & TSS \\
\hline MaxEnt & 0.769 & 0.609 & 0.699 & 0.424 & 0.816 & 0.532 \\
\hline GARP & 0.839 & 0.598 & 0.769 & 0.422 & 0.858 & 0.487 \\
\hline
\end{tabular}

Numbers in brackets refer to the proportion of occurrences used in the training/test subsets in all modeling procedures TSS values consider the LPT threshold, SD standard deviation 


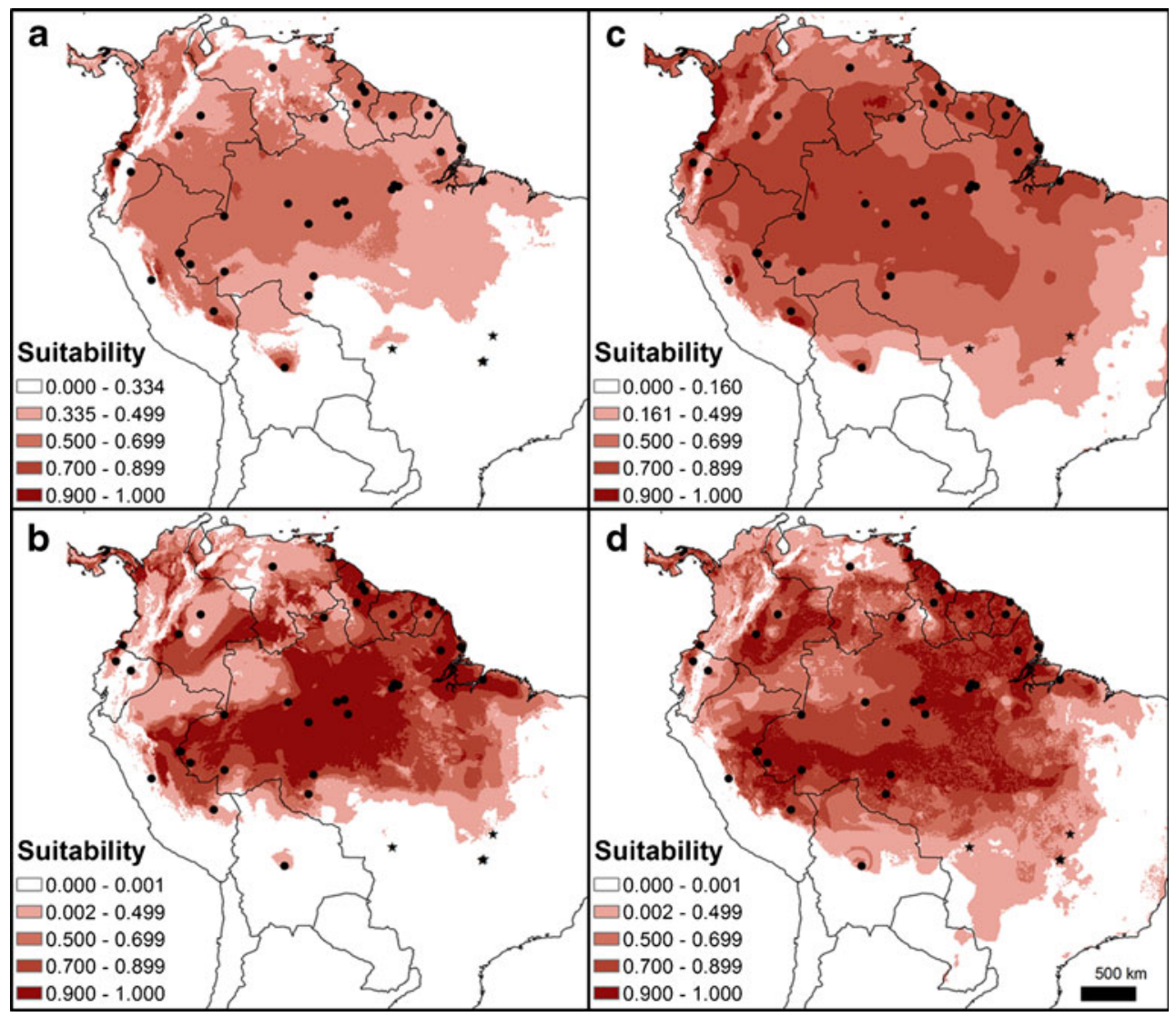

Figure 2. Distribution models generated by MaxEnt (a, c) and GARP (b, d) using only the previous (left) or both the previous and the newer occurrences from the Cerrado (right) in the training subset to predict $A$. caerulea potential distribution. Circles refer to the previous $A$. caerulea's known records; stars refer to the new occurrences found in the Cerrado Biome; question marks refer to the doubtful Panamanian occurrence.

hand, although the ROC threshold minimized $A$. caerulea distribution in those areas, it did not predict the new occurrences sampled in the Cerrado as suitable for $A$. caerulea distribution. Nevertheless, neighboring areas near those new occurrences were predicted as suitable (Figure 3b).

\section{DISCUSSION}

In this study, we presented three new occurrences for A. caerulea, a rare Euglossini bee species from South America, and modeled its distribution considering these additional records. We showed that the doubtful Panamanian occur- rence (Cameron 2004) is suitable as an occurrence record and that $A$. caerulea distribution range, previously believed to be restricted mostly to the Amazon basin (Cameron 2004), also includes some portions of the Brazilian Cerrado. These results have important implications for understanding the dispersal and distribution of Euglossini bees in South America.

As the second largest biome and the largest savanna in South America (Ab'Saber 1977), the Cerrado separates two important biomes: the Amazon and the Atlantic forests. Despite its usual xeric-like environment, it commonly bears evergreen gallery forests near rivers and streamlets. Studies with plants (Méio et al. 2003), 


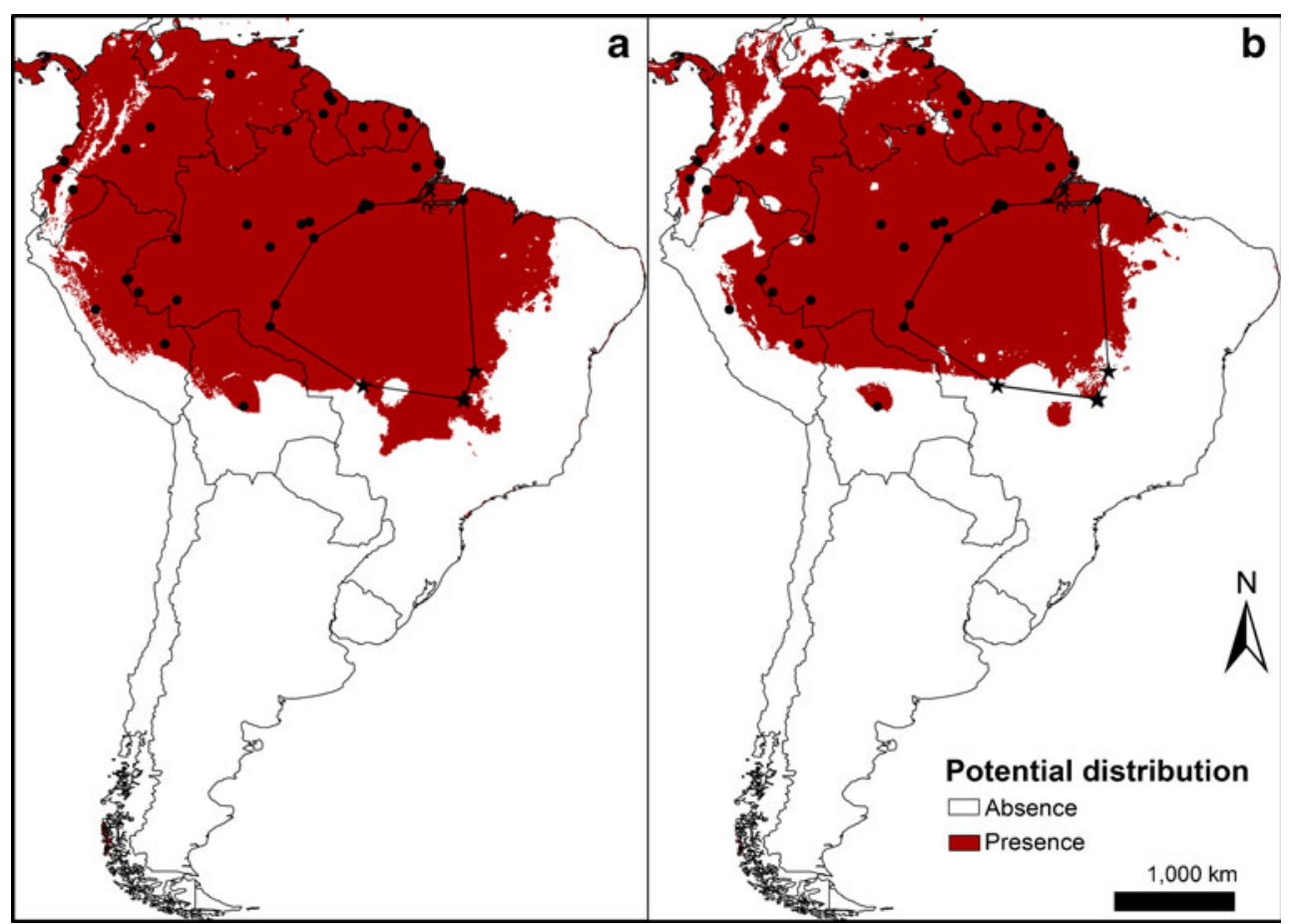

Figure 3. Mean ensemble forecast produced by MaxEnt and GARP considering both a LPT and b ROC thresholds. Note that semi-desert areas in northern Colombia and northwestern Venezuela are not predicted as suitable when we consider only the ROC threshold. The depicted polygon in $\mathbf{a}$ and $\mathbf{b}$ refers to areas where future surveys for A. caerulea in gallery forests should take place. Circles refer to the previous A. caerulea's known records; stars refer to the new occurrences found in the Cerrado Biome; question marks refer to the doubtful Panamanian occurrence.

birds (Silva 1996), butterflies (Brown Jr 1987; 1992), mammals (Redford and Da Fonseca 1986), and solitary bees (Aguiar and Melo 2007) have already suggested the importance of the gallery forest while facilitating dispersal of species dwelling either in the Amazon or in the Atlantic Forest. In Cerrado, gallery forests provide important habitat conditions which allow Euglossini bees (and insects associated with mesic environments) to easily disperse (Moura and Schlindwein 2009). They also provide humidity for the development and establishment of orchid plant species, which are generally used by the males of Euglossini bees as scent sources (Dressler 1982). Such dependence on the gallery forest to disperse in the Cerrado may be the reason why other insects species previously thought only to inhabit in the Amazon were recently sampled in Cerrado (see Almeida et al. 2010 for an example). Although large rivers within the Cerrado (e.g., Araguaia and Paranã rivers) may act as important dispersal barriers for non-flying organisms (Cáceres et al. 2008), such barriers may not restrict the dispersal of Euglossini bees, given their excellent flight capacities and uncommon vagility (Janzen 1971).

The distribution model trained only with the previous, mostly Amazonian, occurrences did not predict the newer Cerrado records and even the model with all occurrences predicted the observed Cerrado occurrences as minimally suitable for $A$. caerulea. The newer records appear to be outliers in the environmental niche parameters of the known $A$. caerulea records, which explain the low predictive power for these occurrences. Similar results were 
also observed for the modeled distribution of other Amazonian species sampled within the Cerrado (Almeida et al. 2010), as well as for other Euglossini bees sampled outside their previously known ranges (Hinojosa-Díaz et al. 2009).

At first, these results may indicate that $A$. caerulea populations in Cerrado are in fact sink populations (Pulliam and Danielson 1991; Pulliam 2000), since the suitability in these areas support the prediction of the occurrence under the LPT threshold (but at minimal values) and was predicted as absent under the ROC threshold. Considering the distribution of habitat suitability, only sites deep in the Amazon (areas with high habitat suitability) would be considered as source populations. Nevertheless, the predicted suitability may not correspond to the true habitat suitability, as perceived by $A$. caerulea bees. For instance, Anjos-Silva et al. (2006) sampled eight $A$. caerulea bees in a gallery forest within the Cerrado, with vegetational features similar to both the Amazon and the Atlantic forest (sensu lato) (Pinto and Oliveira-Filho 1999). In Cerrado gallery forests, either minimally or not predicted as suitable, we sampled two specimens of $A$. caerulea (Silvânia County, Goiás state). Therefore, the dependence on gallery forests of Euglossini bees (Moura and Schlindwein 2009) may significantly increase $A$. caerulea habitat suitability within the Cerrado, a biome which naturally harbor low Euglossini bees diversity (Nemésio and Silveira 2007).

A biased sampling effort in different habitats (Kamino et al. 2011) may underestimate species distribution, affecting the predicted suitability in the new occurrence records (Almeida et al. 2010). Therefore, in order to validate both models and generate thresholds for binary prediction based in true absences instead of computer-generated pseudo-absences, future surveys should be performed either in areas where model suitability was low or where the species does not occur.

Considering the known Euglossini sampling effort in South America, the arid areas in northern Colombia and northwestern Venezuela, as well as the dry forests in northwestern Peru and southern Ecuador, are good candidates for further evaluation of the models, since they seem too dry to be considered suitable for the occurrence of $A$. caerulea
(GAR Melo, unpublished data). Nevertheless, considering the strong association of Euglossini with mesic environments, future sampling surveys in the humid formations found in those dry areas should be considered in order to validate model predictions, independently of the thresholds and modeling algorithms used. Future field surveys should also take place in gallery forests found in the area comprehending the southeastern Para and Amazonas states, as well as northern Mato Grosso and Tocantins states, areas predicted as suitable in the consensus maps considering both the LPT and the ROC thresholds (polygon shown in Figure 3a, b).

Although standardized sampling protocols may be considered inefficient on sampling rare species, the continuous use of ENM techniques, whenever new occurrences for rare species are discovered, may improve our knowledge on their distribution range. Such strategy for rare species has been used with success elsewhere (Raxworthy et al. 2003; Pearson et al. 2007; De Siqueira et al. 2009) and should be used continuously as it will optimize to a large extent the amount of resources invested in field surveys (Guisan et al. 2006). Similar approaches to this study should also be considered to other South American Euglossini species sampled outside their previously known distributions (Anjos-Silva 2008; Silva and Rebêlo 2009), in order to properly assess the distribution patterns of these species and pinpoint notsampled but potentially fruitful areas for future surveys. This suggestion is particularly appropriate for areas of poor knowledge on Euglossini diversity, such as those in the Brazilian Cerrado (Nemésio and Silveira 2007). Despite plenty of studies on Euglossini bees in humid environments from South America (e.g., Mata Atlântica and the Amazon Forest), very few systematic studies have been carried out in dry areas of the continent, as well as in gallery forests within these biomes, which may bear a still unknown Euglossini diversity. Therefore, we advise future surveys of Euglossini bees to be conducted in gallery forests of such environments in order to fill a 
gap on our current knowledge of the distribution patterns of orchid bees.

\section{ACKNOWLEDGMENTS}

We would like to acknowledge John S. Ascher, from the American Museum of Natural History, and Eduardo Almeida, from Coleção Camargo USP-RP, and Kelli Ramos, from Museu de Zoologia da USP, which provided us with several A. caerulea occurrence records. We are also grateful to two anonymous reviewers which provided valuable comment to a previous version of this manuscript. DPS received a doctorate scholarship from Conselho Nacional de Desenvolvimento Científico e Tecnológico (CNPq). PDM and GARM have been continuously supported by CNPq grants. EJAS was supported by Coordenação de Aperfeiçoamento de Pessoal de Nível Superior (CAPES; PQI 0053/02-3), CNPq (473857/03-0), and FAPEMAT (737955/2008; 258060/2010). DPS and PDM would also like to thank the Fundação "O Boticário" de Proteção à Natureza, CNPq, and Whitley Wildlife Conservation Trust for the resources which allowed them to execute the field surveys and discover the three new occurrences for A. caerulea in the Cerrado savanna.

Espèces amazoniennes à l'intérieur du Cerrado: nouvelles observations et répartition potentielle pour Aglae caerulea (Apidae: Euglossini)

Amazonie / savanne / corridor de dispersion / modélisation / répartition des espèces

Artyen aus dem Amazonasgebiet in der Cerrado-Savanne: Neue Funde und Angaben zum potentiellen Vorkommen von Aglae cearulea (Apidae: Euglossini)

Amazonien / Cerrado / Verbreitungskorridor / Wallace'scher Fehler / Modellerstellung zur Artenverteilung

\section{REFERENCES}

Ab'Saber, A.N. (1977) Os domínios morfoclimáticos da América do Sul. Primeira Aproximação. Geomorfologia 52, 1-21

Aguiar, A.J.C., Melo, G.A.R. (2007) Taxonomic revision, phylogenetic analysis, and biogeography of the bee genus Tropidopedia (Hymenoptera, Apidae, Tapinotaspidini). Zool. J. Linn. Soc. 151, 511-554
Allouche, O., Tsoar, A., Kadmon, R. (2006) Assessing the accuracy of species distribution models: prevalence, kappa and the true skill statistic (TSS). J. Appl. Ecol. 43, 1223-1232

Almeida, M.C., Côrtes, L.G., De Marco Jr, P. (2010) New records and a niche model for the distribution of two Neotropical damselflies: Schistolobos boliviensis and Tuberculobasis inversa (Odonata: Coenagrionidae). Insect Conserv. Divers. 3, 252256

Anjos-Silva, E.J. (2008) Discovery of Euglossa cognata Moure (Apidae: Euglossini) in the Platina Basin, Mato Grosso State, Brazil. Biota Neotropical 8, 80-83

Anjos-Silva, E.J., Camillo, E., Garófalo, C.A. (2006) Occurrence of Aglae caerulea Lepeletier \& Serville (Hymenoptera: Apidae: Euglossini) in the Parque Nacional da Chapada dos Guimarães, Mato Grosso State. Brazil. Neotrop. Entomol. 35, 868-870

Barve, N., Barve, V., Jiménez-Valverde, A., Lira-Noriega, A., Maher, S.P., Peterson, A.T., Soberón, J., Villalobos, F. (2011) The crucial role of the accessible area in ecological niche modeling and species distribution modeling. Ecol. Model. 222, 1810-1819

Bawa, K.S., Kress, W.J., Nadkarni, N.M. (2004) Beyond paradise-meeting the challenges in tropical biology in the 21st century. Biotropica 36, 276-284

Bini, L.M., Diniz-Filho, J.A.F., Rangel, T.F., Bastos, R.P., Pinto, M.P. (2006) Challenging Wallacean and Linnean shortfalls: knowledge gradients and conservation planning in a biodiversity hotspot. Divers. Distrib. 12, 475-482

Brooks, T.M., Mittermeier, R.A., Da Fonseca, G.A.B., Gerlach, J., Hoffmann, M., et al. (2006) Global biodiversity conservation priorities. Science 313, 58-61

Brown Jr., K.S. (1987) Biogeography and evolution of Neotropical butterflies. In: Whitmore, T., Prance, G. (eds.) Biogeography and Quaternary History in Tropical America, pp. 66-104. Oxford University Press, Oxford

Brown Jr., K.S. (1992) Habitat alteration and species loss in Brazilian forests. In: Whitmore, T., Sayer, J. (eds.) Tropical Deforestation and Species Extinction, pp. 119-142. Chapman \& Hall, London

Cáceres, N.C., Casella, J., Vargas, C.F., Prates, L.Z., Tombini, A.A.M., et al. (2008) Distribuição geográfica de pequenos mamíferos não voadores nas bacias dos rios Araguaia e Paraná, região centrosul do Brasil. Iheringia. Sér. Zool. 98, 173-180

Cameron, S.A. (2004) Phylogeny and biology of Neotropical orchid bees (Euglossini). Annu. Rev. Entomol. 49, 404

Cardoso, P., Erwin, T.L., Borges, P.A.V., New, T.R. (2011) The seven impediments in invertebrate conservation and how to overcome them. Biol. Conserv. 144, 2647-2655

De Siqueira, M.F., Durigan, G., De Marco, P.J., Peterson, A.T. (2009) Something from nothing: using landscape similarity and ecological niche modeling to find rare plant species. J. Nat. Conserv. 17, 25-32 
Diniz-Filho, J.A.F., De Marco, P.J., Hawkins, B.A. (2010a) Defying the curse of ignorance: perspectives in insect macroecology and conservation biogeography. Insect Conserv. Divers. 3, 172-179

Diniz-Filho, J.A.F., Nabout, J.C., Bini, L.M., Loyola, R.D., Rangel, T.F.L.V., et al. (2010b) Ensemble forecasting shifts in climatically suitable areas for Tropidacris cristata (Orthoptera: Acridoidea: Romaleidae). Insect Conserv. Divers. 3, 213-221

Dobrovolski, R., Diniz-Filho, J.A.F., Loyola, R.D., De Marco, P.J. (2011) Agricultural expansion and the fate of global conservation priorities. Biodivers. Conserv. 20, 2445-2459

Dressler, R.L. (1982) Biology of the orchid bees (Euglossini). Annu. Rev. Ecol. System. 13, 373-394

Elith, J., Phillips, S.J., Hastie, T., Dudík, M., Chee, Y.E., et al. (2011) A statistical explanation of MaxEnt for ecologists. Divers. Distrib. 17, 43-57

Giannini, T.C., Acosta, A.L., Garófalo, C.A., Saraiva, A.M., Alves-dos-Santos, I., et al. (2012) Pollination services at risk: bee habitats will decrease owing to climate change in Brazil. Ecol. Modell. 244, 127-131

Google Inc. (2012) Google Earth, Google Inc

Guisan, A., Broennimann, O., Engler, R., Vust, M., Yoccoz, N.G., et al. (2006) Using niche-based models to improve the sampling of rare species. Conserv. Biol. 20, 501-511

Guisan, A., Zimmermann, N.E. (2000) Predictive habitat distribution models in ecology. Ecol. Modell. 135, 147-186

Hijmans, R.J., Cameron, S.E., Parra, J.L., Jones, P.G., Jarvis, A. (2005) Very high resolution interpolated climate surfaces for global land areas. Int. J. Climatol. 25, 1965-1978

Hinojosa-Díaz, I.A., Feria-Arroyo, T.P., Engel, M.S. (2009) Potential distribution of orchid bees outside their native range: the cases of Eulaema polychroma (Mocsáry) and Euglossa viridissima Friese in the USA (Hymenoptera: Apidae). Divers. Distrib. 15, 421-428

Hong, S.K., Lee, J.A. (2006) Global environmental changes in terrestrial ecosystems. International issues and strategic solutions: introduction. Ecol. Res. 21, 783-787

Janzen, D.H. (1971) Euglossine bees as long-distance pollinators of tropical plants. Science 171, 203-205

Kamino, L.H.Y., Stehmann, J.R., Amaral, S., De Marco Jr, P., Rangel, T.F., et al. (2011) Challenges and perspectives for species distribution modelling in the neotropics. Biol. Lett. 8, 324-326

Liu, C., White, M., Newell, G. (2011) Measuring and comparing the accuracy of species distribution models with presence absence data. Ecography 34, 232-243

Marmion, M., Parviainen, M., Luoto, M., Heikkinen, R.K., Thuiller, W. (2009) Evaluation of consensus methods in predictive species distribution modelling. Divers. Distrib. 15, 59-69

Mata, R.A., Tidon, R., Côrtes, L.G., De Marco Jr, P., Diniz-Filho, J.A.F. (2010) Invasive and flexible: niche shift in the drosophilid Zaprionus indianus (Insecta, Diptera). Biol. Invasions. 12, 1231-1241

Méio, B.B., Freitas, C.V., Jatobá, L., Silva, M.E.F., Ribeiro, R.P.B. (2003) Influência da flora das florestas Amazônica e Atlântica na vegetação do cerrado sensu stricto. Rev. Bras. Bot 26, 437-444

Michener, C.D. (2007) The Bees of the World. The Johns Hopkins University Press, Baltimore

Morato, E.F. (2001) Ocorrência de Aglae caerulea Lepelier \& Serville (Hymenoptera, Apidae, Apini, Euglossina) no estado do Acre. Brasil. Rev. Bras. Zool. 18, 1031-1034

Moura, D.C., Schlindwein, C. (2009) Mata Ciliar do Rio São Francisco como Biocorredor para Euglossini (Hymenoptera: Apidae) de Florestas Tropicais Úmidas. Neotrop. Entomol. 38, 281-284

Moure, J.S. (1967) A check-list of the known Euglossine bees (Hymenoptera, Apidae). Biota Amazônica 5, 395-415

Munoz, M.E.S., De Giovanni, R., De Siqueira, M.F., Sutton, T., Brewer, P., et al. (2011) openModeller: a generic approach to species' potential distribution modelling. Geoinformatica 15, 111-135

Myers, J.G. (1935) Ethological observations on the citrus bee, Trigona silvestriana Vachal, and other Neotropical bees (Hym. Apoidea). Trans. R. Entomol. Soc. Lond. 83, 131-142

Myers, N., Mittermeier, R.A., Mittermeier, C.G., Da Fonseca, G.A., Kent, J. (2000) Biodiversity hotspots for conservation priorities. Nature 403, 853-8

Nemésio, A., Silveira, F.A. (2007) Diversity and distribution of orchid bees (Hymenoptera: Apidae) with a revised checklist of species. Neotrop. Entomol. 36, 874-888

Newbold, T. (2010) Applications and limitations of museum data for conservation and ecology, with particular attention to species distribution models. Prog. Phys. Geogr. 34, 3-22

Nóbrega, C.C., De Marco Jr, P. (2011) Unprotecting the rare species: a niche-based gap analysis for odonates in a core Cerrado area. Divers. Distrib. 17, 491-505

Otero, J.T., Sandino, J.C. (2003) Capture rates of male Euglossine bees across a human intervention gradient, Choco Region, Colombia. Biotropica 35, 520-529

Pearson, R.G., Raxworthy, C.J., Nakamura, M., Peterson, A.T. (2007) Predicting species distributions from small numbers of occurrence records: a test case using cryptic geckos in Madagascar. J. Biogeogr. 34, 102-117

Peres-Neto, P.R., Jackson, D.A., Somers, K.M. (2005) How many principal components? Stopping rules for determining the number of nontrivial axes revisited. Comput. Stat. Data. Anal. 49, 974-997

Phillips, S.J., Anderson, R.P., Schapire, R.E. (2006) Maximum entropy modeling of species geographic distributions. Ecol. Modell. 190, 231-259 
Phillips, S.J., Dudik, M. (2008) Modeling of species distributions with Maxent: new extensions and a comprehensive evaluation. Ecography 31, 161-175

Pinto, J.R.R., Oliveira-Filho, A.T. (1999) Perfil florístico e estrutura da comunidade arbórea de uma floresta de vale no Parque Nacional da Chapada dos Guimarães, Mato Grosso. Brasil. Rev. Bras. Bot. 22, 53-67

Pulliam, H.R. (2000) On the relationship between niche and distribution. Ecol. Lett. 3, 349-361

Pulliam, H.R., Danielson, B.J. (1991) Sources, sinks, and habitat selection: a landscape perspective on population dynamics. Am. Nat. 137, S50-S66

Raxworthy, C.J., Martinez-Meyer, E., Horning, N., Nussbaum, R.A., Schneider, G.E., et al. (2003) Predicting distributions of known and unknown reptile species in Madagascar. Nature 426, 837-841

Redford, K.H., Da Fonseca, G.A.B. (1986) The role of gallery forests in the zoogeography of the Cerrado's non-volant mammalian fauna. Biotropica 18, 126-135

Serra, B.D.V., De Marco Jr, P., Nóbrega, C.C., Campos, L.A.O. (2012) Modeling potential geographical distribution of the wild nests of Melipona capixaba Moure \& Camargo, 1994 (Hymenoptera, Apidae): conserving isolated populations in mountain habitats. Nat. Conserv. 10, 199-206
Silva, J.M.C. (1996) Distribution of Amazonian and Atlantic birds in gallery forests of the Cerrado region, South America. Ornitol. Neotrop. 7, 118

Silva, O., Rebêlo, J.M.M. (2009) Primeiro Registro de Euglossa stilbonota Dressler (Apidae: Euglossini) fora da Floresta Amazônica: Implicações Biogeográficas. Neotrop. Entomol. 38, 880-882

Soberón, J. (2007) Grinnellian and Eltonian niches and geographic distributions of species. Ecol. Lett. 10, 1115-23

Stockwell, D., Peters, D. (1999) The GARP modelling system: problems and solutions to automated spatial prediction. Int. J. Geogr. Inf. Sci. 13, 143-158

Tylianakis, J.M., Didham, R.K., Bascompte, J., Wardle, D.A. (2008) Global change and species interactions in terrestrial ecosystems. Ecol. Lett. 11, 1351-1363

Vianna, D.M., De Marco Jr, P. (2012) Higher-taxon and cross-taxon surrogates for odonate biodiversity in Brazil. Nat. Conserv. 10, 34-39

Whittaker, R.J., Araújo, M.B., Jepson, P., Ladle, R.J., Watson, J.E.M.A., et al. (2005) Conservation biogeography: assessment and prospect. Divers. Distrib. 11, 3-23 